\title{
Dental myths: a deterrent to dental care seeking behaviors in developing countries
}

\author{
Sabrina P Heglund \\ University of Alberta, (Previously of Aga Khan University), Canada
}

\begin{abstract}
Stories handed down vocally were powerful history records in ancient times. Even medicinal plant knowledge was held secret and told by the traditional healers to those specifically chosen to become healers. No wonder such oral reports are respected and believed as the be all and end all for continuation of life as it was known. After all, humans did prevail and are here to tell the tale. In some instances, these stories or myths can bar the uneducated/illiterate person from preventive care or reduction of harmful substance abuse. Dentistry has no lack of myths and beliefs shared with them by their patients. But there is a scarcity of rigorous studies in this field, possible due to the fact that the nidus for such resides in rural, under developed countries. Although not a comprehensive study of available articles, this paper attempts to present some of the myths unearthed from the literature. Much work remains to be accomplished to support the practice of prevention of diseases rather than the more costly treatment of disease in the large populations of developing countries.
\end{abstract}

\section{Introduction}

When a myth is mentioned, one may say to oneself, "aha, another falsehood" about something, and may begin to think of ways to dispel such a story. In reality, myths are ways to come to terms with something one does not understand. That is how it was in ancient times. Scientific thought was far away in the future and explanations of seasons, misfortune, accidents, and even the shape of the world had to be explained from human to human with little or no real knowledge. Superstition and imagination played a role in coming up with plausible explanations. Myths have become a part of many normal people's lives. Even now, walking under a ladder is joked about, but a social experiment observing people's behavior as they walk towards the ladder can still show that the myth resonates with the person enough to give the ladder a wide berth. Justifiably they may fear paint spillage on their person! Many myths abound and some are ingrained in peoples' daily lives. Myths differ from country to country, and society to society. Some are deep seated having been handed down from generations before, having roots in religion, general ignorance or illiteracy, and family rituals. They can be fun to listen to and try to dispel, but some pervade a society to the point that it affects their attitudes, behavior, and quality of life. Trying to persuade a myth holder about the realities of scientific discovery is a daunting task.

Myths regarding health in general but dentistry in particular- may lead to small society's demise through disease. These diseases could be preterm low birth weight babies [1], and even complications from diabetes and obesity. Unfortunately, incorrect beliefs handed down generation to generation are held in high esteem. They are repeated and take on great importance in many families. Simply educating a person about reality does not really allow them to wholeheartedly embrace what you are trying to explain.

The word "myth" is defined as a popular belief or tradition that has grown up around something or someone, according to the Merriam Webster Online Dictionary [2]. Many myths abound around the world regarding many processes, procedures and outcomes. Of interest in this article are the myths that surround teeth and dental procedures. As children we may have been subjected to the threat of "behave or else I'm going to take you to the dentist". Psychologists and psychiatrists have made a comfortable living out of caring for these children as they enter adulthood and have issues with life which may or may not be based on these words heard as children.

Belief in myths does not necessarily lie only in developing countries. Developed countries have their share of myths either initiated in explanations of misunderstood verbal reports or directly propagated from ancestors who have immigrated to their adopted countries. A sometimes forgotten ancestry of myths is those shared by the interdependence of indigenous people with the new comers. As individuals, we have many interactions with many people from many walks of life, and as with a communicable disease, myths can be perpetuated and even morph into stories that are easily adapted to any purpose dealing with life and what life deals out. In some instances, the myth even becomes a source of hilarity or on the dark side, points out strong differences between cultures. This paper offers the reader some myths from developing countries as recorded in the scarce research available that notes these myths as a barrier to oral health seeking activities. It really is not "all about the cost".

\section{Early myths}

Upon entering dental, dental assisting or dental hygiene school, students are slowly inculcated into the art and science of dentistry. Within the first few days the concept of primary tooth shedding and permanent tooth eruption patterns are taught. Around those lessons there are introductions to dental embryology, physiology, dental

${ }^{\star}$ Correspondence to: Sabrina P Heglund, University of Alberta, Canada, Tel: 587-372-8871; E-mail: sheglund@ualberta.ca

Received: September 25, 2018; Accepted: October 03, 2018; Published: October 08, 2018 
anatomy and much more. For a student to appreciate the differences in tooth anatomy and the variety of cells forming the supporting structures for those teeth, details about the hardness and completeness of enamel formation is thoroughly covered. Around that time, students may recall stories they heard about mothers saying that they lost a tooth for every child they had. Of course the existence of the tooth fairy is questioned as well. Adults know about the latter, but there are many adults who still persist in the belief of losing a tooth for every child.

Although not related to teeth, but a close second for favorite old wives tales is one about what one must do immediately upon getting burned. Most frequently, burns occurred in the kitchen to the mistress doing the cooking, hence the appellation "old wives tales". In early days, refrigeration was carried out with blocks of ice in an icebox where butter was kept from spoiling. As butter was the coldest item and most easily smeared substance, butter was the first-aid go-to for many decades. In developing countries, the go to for a burn was not butter as it was expensive, but toothpaste as it was cheaper, spread well, and may have had peppermint flavoring which felt cool on the burn.

The common cold was blamed on going out with wet hair, or washing your hair and sitting under a fan, or even going to bed with wet hair. Most often, colds begin in the head and sinuses giving credence to the drop in temperature being the culprit. In developing countries, the days are long and hot much to the delight of air-conditioning companies. Rushing out after washing ones hair and sweating while running to the transport, accomplished with a traditional head covering, and then being transported into the air conditioned luxury of an office is held to be the cause of head colds. Winter weather in developed countries still have people believing that cold weather propagates "the flu", not that residences and offices are air tight rooms which heat or cool with re-circulated air. Those of us reading these remarks are probably of the dental persuasion and have learned about the lack of time for oral care in new mothers, ice to cool burns, and viruses propagating rapidly in closed, warm, moist environments.

In countries that are developing, education is scarce and people rely on each other for health remedies due to the fear and cost involved in visiting a doctor. Here even the time taken off work to see a doctor during the day is a blow to the family income. Many of the folks live on the periphery of large cities and have to travel great distances to see a doctor. Doctors in general, whether medical or dental, tend to set up in areas that are prosperous rather than areas where people are living in poverty. Adding a lack of education and the means to get to a doctor propagates many rituals and beliefs that developed countries may not understand.

\section{Some myths in circulation}

There are only a few articles on dental myths available. Much of the information comes from verbal interaction during community dental visits. The information retrieved from dental settings is more structured and contain questions to which answers are presupposed and the questions are verbally asked of the patient. Many of the patients do not read or write their own languages.

One strong belief is the "tooth worm" theory. This is not just restricted to third world countries as many of us have heard of the theory coming down from the Greek and Roman eras. However, much entertainment can be had by a play by play translation of the healer in the village holding a bowl of steaming water to the afflicted side after burning smoke producing herbs (Henbane) that was inhaled by the patient. Bits of frayed string were furtively placed in the water to resemble the worms coming out of the painful tooth.
Cloves have been known to soothe painful teeth. Cloves are a spice used in mulled drinks and chai (tea). As a matter of fact, cloves contain eugenol, a phenyl propene that is used in dentistry mixed with zinc oxide as a temporary filling material believed to calm pain and promote the growth of secondary dentin. Chewing on cloves can help to calm the pain and exudes a pleasing aroma that can equal "medicine for my tooth".

Dental diseases do not cause pain in the early stages, are not life threatening, and can be soothed with a variety of pain killers purchased over the counter, or traditional methods such as the clove. These items offer temporary relief not the cure for incipient caries or abscessed teeth [3], but still may remain the choice of poverty stricken folks. Even abscessed teeth can be treated with over the counter antibiotics that patients use only until the pain subsides, leading to much of the plague of antibiotic resistant bacterial strains.

Some people questioned in the Nasir study [4] were concerned that visiting a dentist might result in them contracting jaundice/hepatitis. In Pakistan, the rates of hepatitis have risen due to the lack of education and awareness of the disease. In an editorial, "Hepatitis C in PakistanA neglected challenge", Dr. Qidwai [5], a prominent doctor in the department of family medicine at the Aga Khan University Hospital in Karachi, quoted Muhammed and Jan [6] when he stated that the general population of Pakistan culturally prefer parenteral treatment over oral medication. In dentistry, the use of anesthetics delivered via parenteral means is a given. In Pakistan there is a shortage of medically qualified and scientifically trained health care workers and a lack of health infrastructure that allows for dental quacks to administer injections with unsterilized equipment. Community stories surfaced more recently when hepatitis awareness was raised in Karachi due to the 2004 launch of immunization for HCV and people who were unaware of such a disease learned more about the consequences of hepatitis B and C.

Teething in children was attributed to fever and diarrhea [7] by $85 \%$ of the sample in a cross sectional national study in Jordan. The results led the researchers to believe that knowledge of teething was low or non-existent. The Nasir study found the same results and had also collected information on the levels of education the parents presented with. Those with lower than a matriculation or no schooling at all believed the fever, diarrhea, drooling, respiratory problems and ear rubbing was caused by the eruption of primary dentition. Nasir, et al. pointed out that at the time of primary tooth eruption, the children were practicing crawling and other forms of forward propulsion. Children, floors, and fingers in the mouth could be the culprit for the variety of ailments reported and recorded.

Some cultures believe that a child born with teeth become witches. Nagaraj, et al. [8] found that $35 \%$ of educated persons and $46 \%$ of uneducated ones believed this to be true. Raina, et al. [9] in a study carried out in India, found a belief that children born with teeth were harmful to their grandparents. Bankole, et al. [10] wrote about a film produced to dispel the Nigerian belief regarding the presence of a natal or neonatal tooth. The belief is that it is a sign of a curse or an abomination affected on the child and child's family. The grandparents are shunned by the community as allowing their child to engage in some unacceptable behavior that cursed them and the family. Some of the Nigerian midwives studied earlier by Bankole [11] believed natal teeth were caused by evil spirits, stated that children with such teeth behave strangely and some were convinced that the children will develop evil spiritual powers. Due to this, some of the midwives would advise parents to get rid of or hide the child. 
Dental office personnel know about the myth that primary teeth are not important as the child will have an adult tooth come in anyway $[1,12,13]$. Those readers who practice dentistry know that there are important needs for retaining primary dentition until they are exfoliated: space held for permanent teeth, fillings to reduce the reservoir of caries causing bacteria, permanent tooth is congenitally missing, and the progression of caries directly from the primary tooth to the underlying tooth in waiting. In the modern day dentistry practiced in areas where there are rampant primary decayed teeth, the child is put under general anesthesia and stainless steel crowns are fitted to replace bombed out primary teeth. Social acceptance of those children in school and community is sometimes challenged leading to psychosocial disturbances in behavior, besides the large risk of general anesthetics for children in the first place.

Artificial teeth or dentures are believed to be the natural teeth extracted from another human. In the study by Raina, et al. [9], 43.2\% of the participants believed this to be true. The authors did not elaborate much on this concept in the paper, but historically a variety of materials have been used to replace lost teeth. In ancient times, animal teeth and pieces of bone were used in various bases for the replacement of teeth. These early but rather crude prototypes of were carved by hand to appear and to function as natural teeth. Even George Washington was said to have had wooden teeth. Although in "The excruciating history of dentistry: toothsome tales and oral oddities from Babylon to Braces", James Wynbrandt ( $1^{\text {st }}$ ed., New York: St. Martin's press, 1998) wrote that the teeth were actually made of ivory and over time took up stain that gave it the look of wood.

The number of people who believed in the myth of vision loss [14] from the removal of upper teeth was explored by both Raina, et al. [9] and Nagaraj, et al. [8] among many others. Kiran, et al. [15] proposed that in middle age, teeth are lost due to caries or mobility which coincides with the time the patient starts to become short sighted and needing glasses. Cause and effect can be skewed in people's minds especially when they rely on oral history telling due to low level of education and literacy. An alternate reason was postulated: an abscess in an upper tooth may cause swelling under the eye causing closing of the eye. It may lead to the fear that the eye is being infected. Another plausible explanation for such a belief is that the delivery of an infraorbital block injection incorrectly placed can cause the transmission of an electric shock to the orbital nerve and the retelling of the experience caused it to be blown out of proportion.

Many of the articles retrieved regarding dental myths are of great interest to dental hygienists as they perform debridement of calculus and removal of plaque. The myth is that if teeth are cleaned, they become loose, or sensitive, or cause spaces to occur between them. Nagaraj, Nasir, Raina, Kiran, Kahar, et al. [16] and many others have mentioned these and variations on the theme. Those in the field of dentistry can understand where this belief originates and how it get propagated and embellished on the retelling. In addition to the telling of the myth, soreness, sensitivity, mobility, and bleeding may cause the "sufferer" to discontinue all home care efforts thus allowing further accretions and sensitivity problems to occur. So for the myths that get attention in the field of dentistry, there is a more simple explanation to dispel the myth. However, with lower education standards, and the raw fact of lack of time to explain to a serious believer, the myth is sustained and may even gain more followers.

'Placement of tobacco [12] on or near a painful tooth was thought to relieve the pain [17]. The same is believed for analgesic medications.
Tobacco products, such as chewing paan to relieve pain [18] are related to oral cancers and the use of over the counter pain relievers on soft tissue causes chemical burns. Tobacco products are believed to aid digestion (Gender \& Education, 1803), reduce halitosis, clean teeth $[1,16]$, prevent constipation, and deworming. The last leads back to the deworming of the tooth worm! In India it was only in 1992 that a law was passed preventing manufacturers from adding tobacco to dentrifices [16].

Sharma, et al. [4] looked at their study population in India in a slightly different manner with the questioning directed towards who might be to blame for a variety of dental ills. They explored who was responsible for: keeping teeth healthy, tooth pain, swollen gums, difficulty in eating, inability to smile, fun poked at bad condition of teeth. The participants very certainly knew that they were responsible for their own teeth, but if their teeth were made fun of, they took the fatalistic view that it was definitely god's will, not theirs. Surprisingly, the statistics showed that women believed in god's will and that they have less fear because of their strong faith in the religion more so than men.

Sharma, et al. (2016) [14] wrote about the majority of participants in their study believing that swelling from a painful tooth should be fomented with hot water. This practice does not reduce pain, but it may inadvertently lead to cellulitis in some cases $[19,20]$. Lesions occurring from periapical/ endodontic sources may remain within the alveolar bone but can also drain intraorally or extraorally through soft tissue fistulas. When a warm facecloth is placed in the area of an acute periapical lesion it tends to cause swelling and may draw out the exudate from the lesion by sheer pressure. These types of infections can scar extraorally and if not treated, may cause further infections in the facial areas that need emergency attention.

In Brazil [21] the resulting scars on the lower cheeks and chin left after the infection has cleared have been called poverty scars. Status in the country is judged not by bank accounts, but the condition of the teeth. Therefore, a poverty scar brands the person as a have-not. Marriage proposals become non-existent if a girl has a poverty scar or a snagged tooth, missing front teeth, as does the chances of getting a paying position. The authors also spoke of "hammering-the-pointpedagogy" meaning that the message of brushing and cleaning must have been learned by the "ignorant and un-educated person" due to the number of times they have been told such things. After numerous dental visits where the teeth are disclosed for plaque detection, the patient is berated and made to feel worse about their condition. This causes a barrier to patients returning for further hammering of the same point. One of the project dentists stated that she would rather extract teeth than place a filling. The reason was that the pain was the sharpest at the time of extraction and did not occur again as in if a filling was placed and it fell out.

The Brazilian people also believe in the worm theory. The people use the power of prayer, invocation to saints, perfumes and plants to stop the evil writhing of the worm's tail. They believe that the worm also can widen the hole to escape out of that black hole and when that happens the pain stops. Just the blackened, hollowed out tooth remains in the socket. A visit to the dentist has become an act of courage as the masked dentists have rituals of orders, such as "spit", "rinse" and then draw out heavy stainless steel tools so that the patient feels like he has come to "the chair" for death-row termination of life of the tooth. Women are seen to be more courageous than men because they have already encountered the even worse pain of childbirth. 
Garcha, et al. [3] referred to the many times mass immigration of the waiting relatives and friends of the patient into the operatory when the patient is called! The treatment rooms are crowded and the chances of infection control being breached are heightened. The underlying myth for this behavior is that the patient does not want to be outnumbered by the treatment personnel, do not want to be railroaded into extra treatment, and surrounding themselves with people like themselves insulates them from being taken as unclean in the cleanliness and asepsis of the operatory.

Other barriers explored were specialized professionals take more money while traditional healers are happy with less, lack of government policies for payment and time off work, no Sunday clinics, possibility of even more serious physical problems being diagnosed, the need for appointments rather than dropping in when in pain, and that cleaning loosens teeth while maxillary extractions cost sight. Garcha has hit upon all the major points related to lack of education, poverty, culture, government lack of interest and many of the other points related by the other authors.

Gambhir, et al. in their 2016 [12] paper spoke with people in northern India and had a few more tales to report. Rotten teeth were hereditary to $70 \%$ of their participants, the sun should be worshiped for better teeth was true for $60 \%$, refraining from cleaning teeth when gums bleed was supported by $70 \%$, sweets cause decay $80 \%$, baby teeth when exfoliated and thrown on the roof of the house leads to strong adult teeth $60 \%$, no dental treatment while pregnant $58 \%$, loss of teeth due to aging $65 \%$, tooth problems not serious- so neglect is fine $68 \%$, and miswak (tree stick) better to clean teeth than toothbrush $50 \%$. Dental practitioners may or may not have heard these specific reports, but when they are heard, real, scientific information quickly comes to mind. We believe in research and scientific studies because we have been educated in the dental profession and read the literature or been told about the studies. We may call ourselves science seekers, but we have been exposed to and educated in ways that are very different from those in developing countries.

Poverty, and government corruption runs rampant in developing countries. With our study of behavioural theory [22], basic needs for the large populations in these countries have not come close to being met. Worries about food, housing, drinking water, safety have out ranked the need for preventive measures for self-health. Dental care seeking behaviours are lower than medical health emergencies. Visits to medical doctors rarely involve an oral examination unless a specific tongue or throat issue is reported. Systemic health initiated or diagnosed in the oral cavity is largely ignored in developed countries and dental hygienists have made concerted efforts to address such separations. In developing countries, efforts made to reach people in rural areas are sometimes thwarted for reasons such as, "we never had blood pressure problems and were not sick until you came and examined us". Many outreach efforts were seen in that light and a free oral cancer scan was aborted for a quick decayed, missing or filled primary tooth index. Recommendations can be made to visit a dentist, but people have no money to do so and dentists rarely give away their services in these countries.

\section{Conclusion}

Although modern medical science has advanced more than it was a few centuries ago, a large portion of the world population has not developed psychologically or spiritually to maturely seek out information available on mass media or in books [3]. More time is spent conversing about people and events than that spent on reading or knowledge seeking activities. People tend to believe hearsay and prefer to be told about other's logic than to look it up for self. It is convenient, time saving, and conserves energy, plus it promotes the conviviality of gregarious folks wholeheartedly believing in traditional stories and customs sometimes even more than in their religion [3]. It will take great effort over decades to reach the underserved populations in developing countries. Many of the articles read for this paper, say that the general population follows the belief that if nothing averse happens to family members even if they smoke and don't keep their mouths clean, it won't happen to them either [18]. They are not educated in the susceptibility of different individuals due to their genetic make-up, and are not made aware that even relatives of patients with oral cancers have the same risk for cancer as the rest of the population. For now, myth, traditional healers, and home remedies hold sway.

\section{References}

1. Vignesh R, Priyadarshni I (2012) Assessment of the prevalence of myths regarding oral health among general population in Maduravoyal, Chennai. J Educ Ethics Den 2: 85.

2. Merriam-Webster I (2008) Merriam-webster online dictionary. Springfield, MA.

3. Garcha V, Shetiya SH, Kakodkar P (2010) Barriers to oral health care amongst different social classes in India. Community Dent Health 27: 158.

4. Nasir Z, Ahmed W, Iqbal F, Iqbal S, Tariq M, et al. (2014) Prevalence of Social Myths and Taboos Related to Dental Health Among General Population of RawalpindiPakistan. Pakistan Oral \& Dental Journal 34.

5. Qidwai W, Fahim A, Waheed S (2010) Hepatitis C in Pakistan - a neglected challenge. Int $J$ Hepatol 1: 5-7.

6. Muhammad N, Jan MA (2005) Frequency of hepatitis "C" in Buner, NWFP. $J$ Coll Physicians Surg Pak 15: 11-14. [Crossref]

7. Owais AI, Zawaideh F, Bataineh O (2010) Challenging parents' myths regarding their children's teething. Int J Dent Hyg 8: 28-34.

8. Nagaraj A, Ganta S, Yousuf A, Pareek S (2014) Enculturation, myths and misconceptions regarding oral health care practices among rural female Folk of Rajasthan. Studies on Ethno-Medicine 8: 157-164.

9. Raina SA, Jain PS, Warhadpande MM (2017) Myths and taboos in dentistry. Int J Res Med Sci 5: 1936-1942.

10. Bankole OO, Lawal FB, Ibiyemi O (2017) Development of a Tool for Dispelling Myths Associated with Natal/Neonatal Teeth: "ADUNNI" A Health Education Video in a Native Nigerian Language. Ann Ib Postgrad Med 15: 137-141. [Crossref]

11. Bankole O, Taiwo J, Nasiru O (2012) Attitude and Beliefs of Traditional Birth Attendants to Prematurely Erupted Teeth of Infants in Urban Local Government Areas in Ibadan, Nigeria. Int Q Community Health Educ 32: 355-366.

12. Gambhir RS, Nirola A, Anand S, Gupta T (2015) Myths regarding oral health among patients visiting a dental school in North India: A cross-sectional survey. Int J Oral Health Sci 5: 9.

13. Khan SA, Dawani N, Bilal S (2012) Perceptions and myths regarding oral health care amongst strata of low socio economic community in Karachi, Pakistan. J Pak Med Assoc 62: 1198-1203.

14. Sharma R, Mallaiah P, Margabandhu S, Umashankar GK, Verma S (2015) Dental myth, fallacies and misconceptions and its association with socio-dental impact locus of control scale. IJPPHS 1:15.

15. Kiran GB, Pachava S, Sanikommu S, Simha BV, Srinivas R, et al. (2016) Evaluation of dent-o-myths among adult population living in a rural region of Andhra Pradesh, India: A cross-sectional study. J Dr NTR Univ Health Sci 5: 130.

16. Kahar P, Harvey IS, Tisone CA, Khanna D (2016) Assessment of Oral Health Knowledge, Attitude, Utilization and Barriers toward Professional Dental Care among Adults in Central rural India. OHDM 15: 135-140.

17. Singh S, Shirodka G, Jain R, Dupare R, Banushali N, et al. (2016). Myths related to Dental decay and Tobacco consumption, IJPCDR 3: 9-14.

18. Ain TS, Gowhar O, Sultan S (2016) Prevalence of Perceived Myths Regarding Oral Health and Oral Cancer-causing Habits in Kashmir. 4: 1-5.

19. Passmore R (1947) Mixed Deficiency Diseases in India: a Clinical Description. Trans R Soc Trop Med Hyg 41: 189-206. 
Heglund SP (2018) Dental myths: a deterrent to dental care seeking behaviors in developing countries

20. Brown RS, Jones R, Feimster T, Sam FE (2010) Cutaneous sinus tracts (or emerging sinus tracts) of odontogenic origin: a report of 3 cases. Clin Cosmet Investig Dent 2: 63 .
21. Nations MK, Nuto Sde A (2002) "Tooth worms", poverty tattoos and dental care conflicts in Northeast Brazil. Soc Sci Med 54: 229-244. [Crossref]

22. Maslow AH (1943) A theory of human motivation. Psychol Rev 50: 370.

Copyright: $@ 2018$ Heglund SP. This is an open-access article distributed under the terms of the Creative Commons Attribution License, which permits unrestricted use, distribution, and reproduction in any medium, provided the original author and source are credited. 